\title{
Application of Hybrid FEM-DIC Method for Assessment of Low Cost Building Structures
}

\author{
A. Piekarczuk • M. Malesa • M. Kujawinska • \\ K. Malowany
}

Received: 14 June 2011 / Accepted: 28 March 2012 / Published online: 26 April 2012

(C) The Author(s) 2012. This article is published with open access at Springerlink.com

\begin{abstract}
In this work pre-operating tests of low-cost building structures have been presented. A hybrid experimentalnumerical methodology has been used to determine the influence of an external, environmental load on the overall endurance of a hangar made of self-supporting metal-plates. Numerical simulations carried out on a FEM model have been consequently verified by measurements of the structure performed with the 3D Digital Image Correlation method and as a result, a detailed, calibrated FEM model of the structure has been developed.
\end{abstract}

Keywords Digital image correlation - Displacement measurement $\cdot$ Civil engineering $\cdot$ Hybrid experimentalnumerical methodology $\cdot$ FEM

\section{Introduction}

The collapse of a building may be caused by overcrowding, negligence during the design stage or by an excessive load (e.g. caused by weather conditions). Two of these causes occurred together when an exhibition hall in Katowice (Poland) collapsed in 2004 killing 65 people [1]. The roof of the structure was overloaded by the presence of a thick layer of snow. That is just one example among many low

\footnotetext{
A. Piekarczuk

Building Research Institute,

1 Filtrowa St.,

00-611, Warsaw, Poland

M. Malesa $(\bowtie) \cdot$ M. Kujawinska $\cdot$ K. Malowany

Warsaw University of Technology,

Institute of Micromechanics and Photonics,

8 Sw. Boboli St.,

02-525, Warsaw, Poland

e-mail: m.malesa@mchtr.pw.edu.pl
}

cost building structures (temporary exhibit halls, storage buildings etc.), whose collapse can lead to tragic events. For designers of such structures, the priority is to minimize building costs (incl.: design, materials, preliminary tests) and therefore they often exhibit relaxed norms in regard to safety. At the same time, the maintenance costs are being cut, so assessment of the health of the structure is minimized or not performed at all.

An another cause of a building failure can be the lack of sufficient engineering knowledge, particularly when a new, specific design is applied in an inadequate environment. A typical example of such structures is a hall's arch (Fig. 1(a)) [2]. The arch is made of a graded metal plate, whose thickness varies from $0.7 \mathrm{~mm}$ to $1.5 \mathrm{~mm}$. The typical dimensions of a single module are $60 \mathrm{~cm} \times(12 \div 24 \mathrm{~cm})$. Individual segments are connected by kneading unbounded edges or by screws. A curved surface which is being formed from the segments has a length equal to the multiplied length of a singular module. The metal plate shaping technology causes the characteristic goffer pattern to appear on the surface of an object.

Graded metal plate structures (span up to $18 \mathrm{~m}$ ) were initially being built temporarily for military applications [3] and were expected to be utilized in homogeneous climatic conditions over a period of a few months. However, the simple and fast technology of manufacturing and assembling called the attention of civilian investors, who adopted the technology to build bigger objects (span up to $30 \mathrm{~m}$ ) with the purpose of civil engineering applications and with a much longer utilization period.

The straightforward adaptation of the technology combined with parameters and purpose modification causes constructional issues particularly in regard to stability and load capacity. Moreover, the irregular metal plate surface is difficult to be numerically modeled [4] and hence, the local 
Fig. 1 Examples of a structure (a) in good condition, (b) after failure
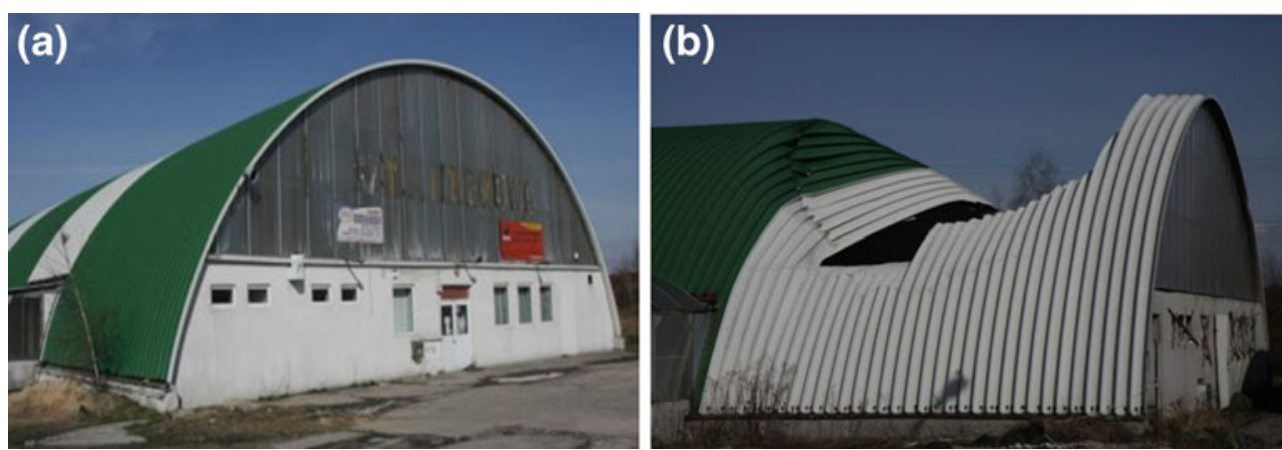

loss of stability can occur in unexpected regions. Furthermore there is a lack of formal regulations (standards, instructions, guidelines), pertaining to methods of calculations of such structures. Simplified designs lead to crucial parameters being left out in the stability analysis which in consequence can lead to a catastrophic collapse. An example of a failure of the hall's arch is presented in Fig. 1(b).

The failure occurred in winter after snowfall. The weight of a thick layer of snow was the direct cause of a loss of stability. During the design stage, local loss of stability and lateral buckling were not taken into account.

SHMs are expensive in maintenance and not very efficient. Also the most commonly used monitoring systems (based on strain gauges, optical fiber sensors, ultrasound imaging) [5-13], utilize pointwise methods. The application of these sensors [14] forces engineers to prepare superfine numerical models and predict crucial points to be monitored, which in many cases is difficult or impossible. Sometimes monitoring is performed by a hierarchical system of full-field methods $[15,16]$, which includes interferometric and noncoherent image-based methods (moire fringe method, fringe projection, digital image correlation) [17, 18]. However, even if the more efficient, full-field techniques are applied, SHM systems are still too expensive to be applied to monitoring of existing low-cost building structures in the course of their utilization. However, it is urgent to answer the question: in what conditions is it safe to exploit such structures?

It is possible to do it off-line through carrying out extensive laboratory tests on a 1:1 scale model in combination with FEM numerical analysis in order to provide a numerical model which is as close to the real structure, as possible [19]. This determines the hybrid experimental-numerical methodology, in which the laboratory measurements are performed to obtain a precise response to the simulated natural load. The closer the overall dimensions of the model are to the dimensions of the true object, the more the results will be immune to scaling error and in consequence the more reliable they will be. Additionally, simulated laboratory conditions enable full control over the load and data acquisition modules. However, despite the obvious advantages, many obstacles appear during the measurements of $1: 1$ scaled models. The main problems are related to the introduction of a load mechanism and the selection of a measurement method. The choice of a method is crucial in many cases and should be made with respect to the most informative parameter that can be measured. A good selection for low cost building structures are displacements, which can be determined by vision-based measurement systems, which are relatively simple and inexpensive. Digital displacement maps can be easily converted to strains, which are the primary object of interest in the assessment of an object.

\section{Hybrid Experimental-numerical Methodology}

A schematic representation of the hybrid experimentalnumerical methodology [19] is shown in Fig. 2.

The geometry of the object, the material and the load characteristics are taken as input. This data makes it possible to develop a simplified FEM model. The model is then used to determine the range of loads and regions, where the possibility of a failure is highest. The simplified FEM analysis is crucial for the consequent steps. The indicated range of permitted loads is used for the design of the loading system, while the most probable regions of failure determine the localization of the field of view of measurement equipment. Once the areas of interest are defined, the measuring methods, which determine the real displacement of the structure in the selected areas of interest (AOI) need to be chosen. The goal is to obtain mutually complementing data from pointwise and full-field sensors, which can be easily compared with FEM analysis.

The data obtained in the course of the experiment is used to develop a detailed FEM model, which is the output of the hybrid measurement method. The result of the comparison between the experimental and numerical data is put back into the method as a feedback information signal. If the FEM model analysis does not match the experimental results, more tests need to be performed in order to complement the numerical model, which is modified after each experiment loop. 
Fig. 2 A block diagram of the hybrid experimentalnumerical procedure (a)

(b)

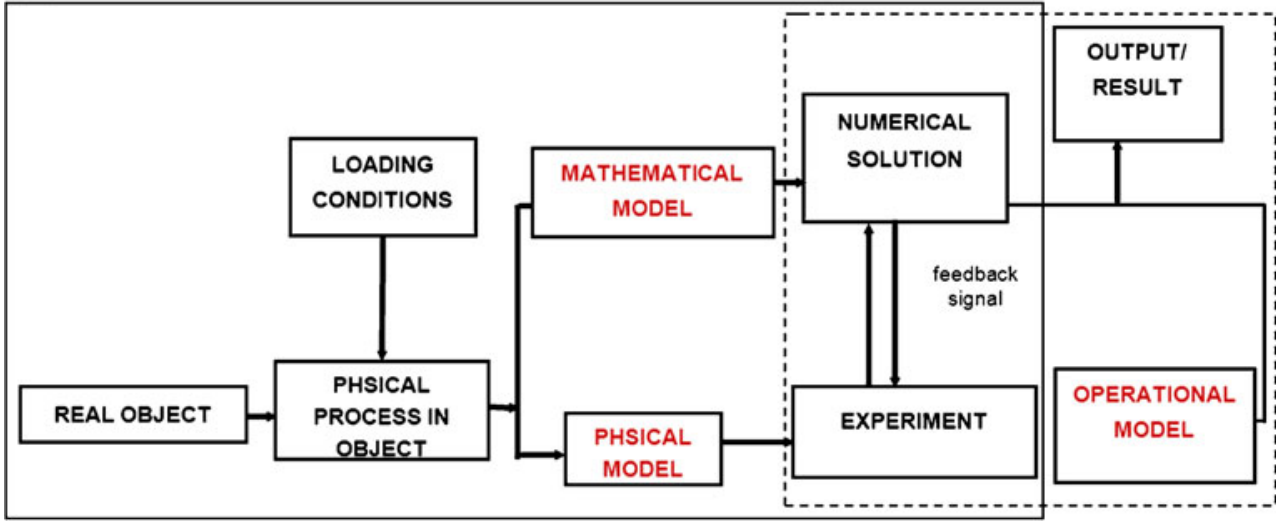

\section{Description of the Object}

The real-world object, its physical model and two FEM models will be described in this section.

The Real-world Object and its Physical Representation

The object (Fig. 3(a)) is a part of a warehouse complex and its construction is that of a self-supporting roof, founded directly on a continuous spread. The span of the hall is $12 \mathrm{~m}$ and the length is $45 \mathrm{~m}$. The roof does not have an insulating layer and the hall is not heated. The top-side walls are made of cold-formed profiles (pillars, spandrel beams), covered by a trapezoidal metal-plate.

The specimen used in the experiment was a part of a metal plate arch composed of four individual modules (Fig. 3(b)). Each module was made of a 1,25 mm thick, S355 steel cold-milled metal plate, which was composed of $3 \mathrm{~m}$ length segments. The segments were connected with M6 bolts. The dimensions of the cross-section of the metalplate are presented in Fig. 3(c). The arch was fixed to the steel beam through a gusset, which was mounted with a dowel bar to the concrete foundation.

\section{Simplified FEM Model}

Before the laboratory tests were performed, a preliminary analysis of the simplified, computational bar FEM model (reduced to a singular arch module) had been carried out. The arch was divided into 36 line segments, which is sufficient for deformation estimation and determination of the maximal inner forces (bending moments and compression forces). A mesh grid was generated using the Coons method. The arch was pin jointed. The elasticity of support has been determined through experiments on an universal testing machine. The aim of the preliminary analysis was to determine a substitute load of a thick layer of snow and to establish regions to be observed by sensors. The analysis was carried out using the simplified model, as the gofferings on the metal plates could not be described mathematically and were impossible to model. The gofferings introduced geometrical orthotropy, (despite the material being

Fig. 3 The object and its physical model: (a) a photo of a part of the warehouse complex, (b) the experimentally investigated object and (c) the dimensions of an individual module
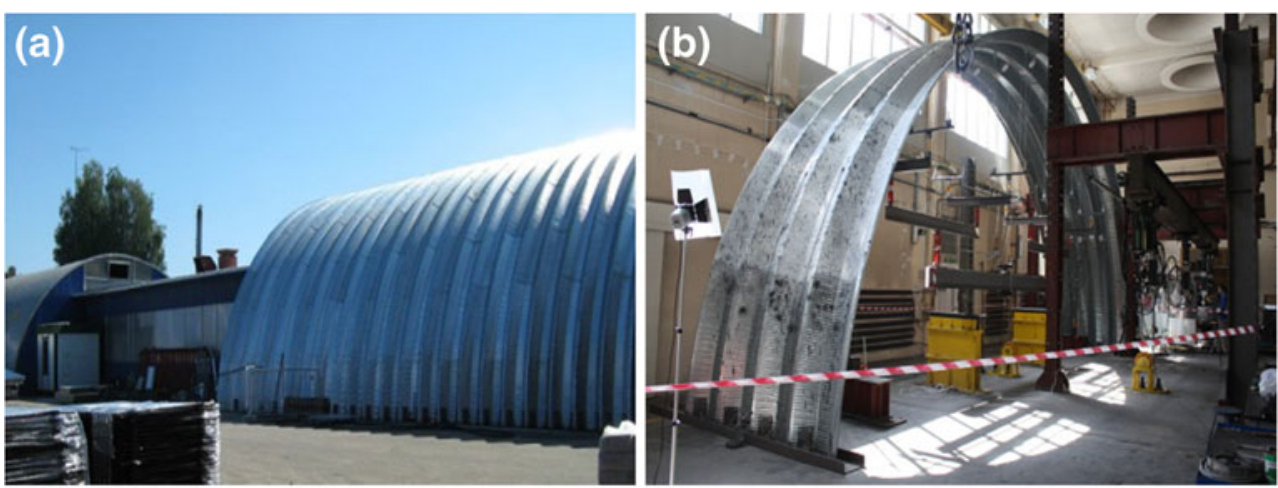

(c)

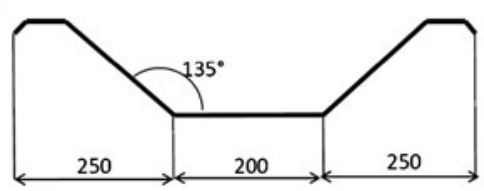




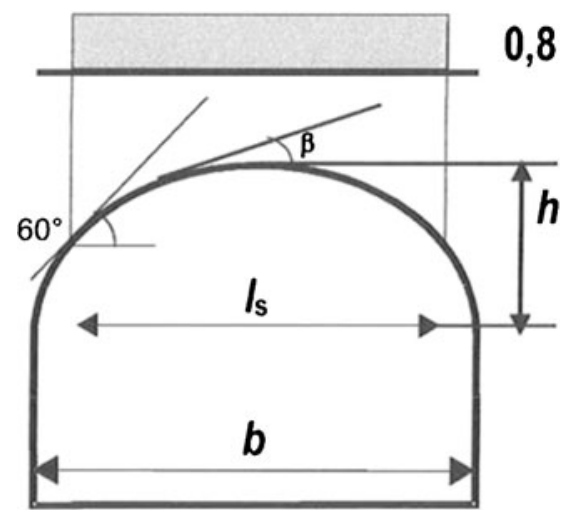

Fig. 4 The general load distribution scheme

isotropic) whose influence had to be accounted for through the course of the experiment. The introduced load was distributed uniformly, as shown in Fig. 4.

A linear load (Fig. 4) was introduced by four aggregated forces. It was assumed (based on additional research), that if the inner forces and deformations caused by the introduced, equivalent load are correlated with the inner forces and deformations caused by the linear load, then the load conditions are modeled properly. Second-order analysis was utilized in order to take the flexural buckling phenomenon into account. In this case, the load and inner forces' values do not contribute to the dimensioning of the structure but are used solely for the comparison of their consequences. An example distribution of bending moments and deformations introduced by the equivalent load has been presented in Fig. 5(a) and (b) respectively.

The normal and shearing forces were also taken into account in the analysis. The effects introduced by the linear and equivalent loads are comparable, so the selected model is assumed to be correct. The deformation of the arch indicates regions with maximum displacements, which occur in the mid-height and the mid-span, at both sides of the arch (the same region as the maximum bending moment). These regions were chosen as target positions for the inductive displacement sensors, strain gauges and the field of

Fig. 5 (a) The bending moments and, (b) deformations introduced by the equivalent load view of the digital image correlation sensor. The strain gauges (SG) were placed in locations of maximal interaction of bending and compression forces and inductive displacement sensors (DS) were placed in the same region in locations of maximal deformations. The region of interest selected for DIC included the locations of the strain gauges and displacement sensors.

The simplified FEM model was utilized to check the correctness of the equivalent load and to indicate the regions to be observed by sensors. The simplified bar model does not take the detailed support conditions and the local loss of stability into account. These problems are the subject of laboratory tests and further calculations based on the detailed, shell FEM model.

\section{Detailed FEM Model}

The detailed FEM model was developed as a spatial cover with dimensions consistent with the dimensions of the test object. The cover was modeled as a curved, orthotropic surface. The orthotrophy directions were perpendicular to the goffering and their values were determined on the basis of preliminary tests of the metal plate fragments. The results of those tests have been presented in Fig. 6 .

The material was isotropic, but the orthotropy was introduced to the measured object by the goffering of its surface. The specimen used for preliminary tests was a fragment of the metal plate. The width of the specimen was $100 \mathrm{~mm}$, its length was $300 \mathrm{~mm}$ and its thickness was $1 \mathrm{~mm}$. The specimen was subjected to tension crosswise to the goffering. It was assumed that the goffering influences stiffness in the transverse direction only, while the stiffness in the lengthwise direction of the goffering remains unchanged compared to the flat metal plate. Test results have been compared with results of similar tests carried out with a flat metal plate specimen with identical dimensions. The orthotropy coefficient was estimated as 0.85 and it has been used to modify the stiffness matrices. The cover was elastically supported at the location of the gusset plate. The elasticity of (a)

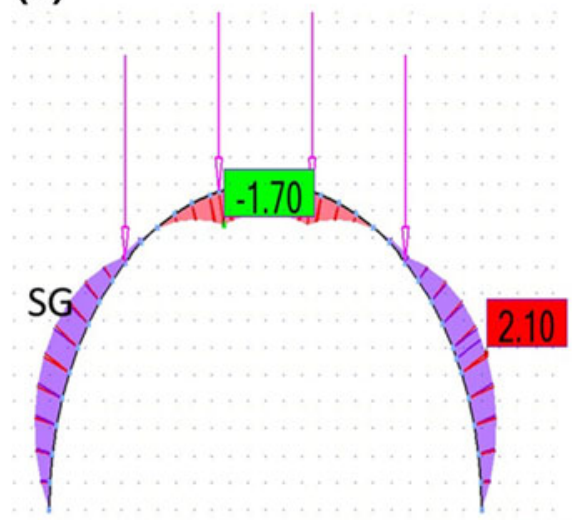

(b)

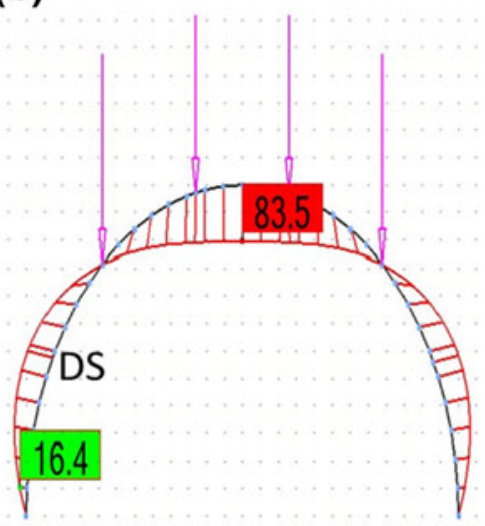


Fig. 6 Results of preliminary tests of metal plate fragment

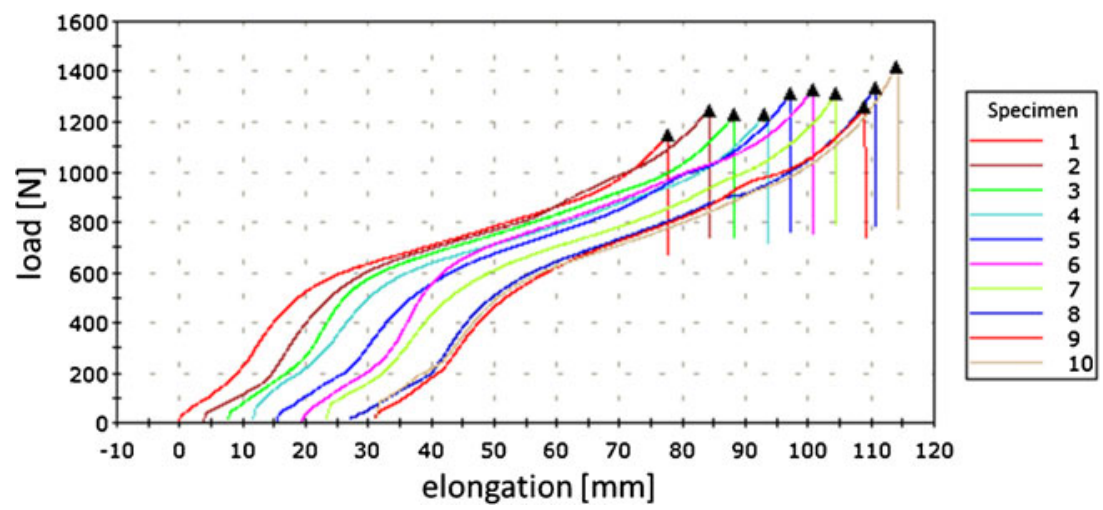

the support was determined on the basis of the test results. The equivalent load was introduced to the surface of the cover through a diaphragm (a rigid body model), whose dimensions corresponded to the clamping metal plate.

The calculations were performed in two variants: in the first one, the aim was to determine the critical load and buckling form, while the second one was a nonlinear, static analysis, which aimed to determine the displacements and stress maps in the most significant regions of the structure.

In Fig. 7 the detailed calibration procedure of the model is presented.

The experimental and numerical results were referenced to the selected model's regions as a function of load. Linear analysis does not take into account the local instabilities, nor the cross-section orthotropism and provides comparable results only in the initial linear range up to point A. The discrepancies produced by the linear model in reference to the experiment are too big and thus it is not suitable for calibration outside the linear region. The results of the nonlinear FEM calculations are non-linear, which is due to second-order effects, geometrical cross-section orthotropy and geometrical imperfections. An increase of the load causes local stability variations, which are dependent on the range and character of the geometrical orthotropy. The discrepancies between the experimental results and numerical simulations are manifesting at point $\mathrm{B}$. The specific cause of this phenomenon is uncertain, thus it is imprudent to assume the FEM model as suitable for further evaluation. At this stage it was asserted that the discrepancy between experimental and numerical results cannot exceed the maximal measurement uncertainty of the investigated object, which was approximately $10 \%$ within the analyzed loading range. The assertion is valid up to point $\mathrm{B}$. In consequent points, the discrepancies exceed the acceptance level and an iterative procedure is utilized in order to correct the model. The first correction is carried out at point $\mathrm{C}$, shifting the curve within the $\mathrm{B}-\mathrm{C}$ range by the " $1-2$ " value, making the result coincide with the point $\mathrm{B}$. The correction is made by modifying the flexural and membrane stiffness matrices of the numerical model. The aim is to diminish the gap between displacements obtained from the experiment and from numerical simulations. This operation was preceded by an analysis of supercritical states, with regard to the local instability. Ultimately, the manipulation of the stiffness matrices minimized the divergence between the experimental results and the non-linear FEM model (resulting in the emergence of the corrected model). The non-linear character of the model is preserved over the course of the correction.
Fig. 7 Detailed FEM model calibration procedure

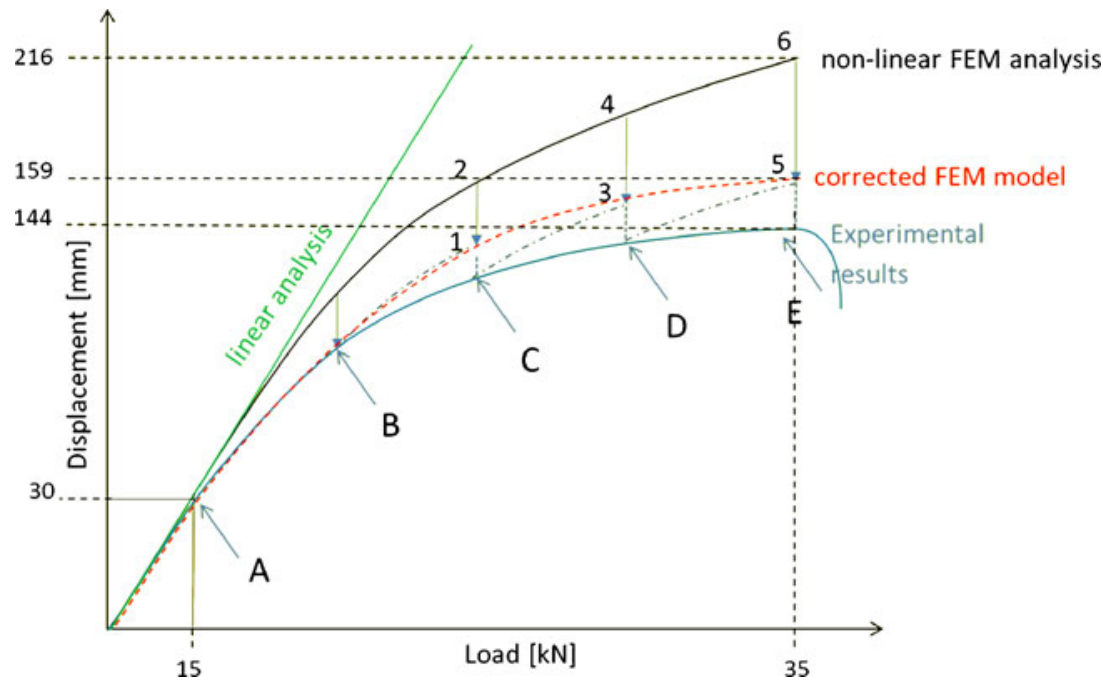


Similar shifts of the FEM model's output were carried out for consequent, higher load states (at point $\mathrm{C}$, the curve shifts the value " $3-4$ ", and at point $\mathrm{D}$ by the value " $5-6$ "). For each correction, the stiffness matrices are updated and can differ from each other. It is justified, as increasing load values introduce variations of local stability. The assumed acceptance level of discrepancies between the experiment and numerical simulations (10\%) is constant and guarantees sufficient correlation between the experimental and numerical results. However, the acceptance level could be made more strict if accuracy requirements are elevated. In such a case, more iterations would have to be carried out. At the last stage of calibration a new, corrected curve is obtained (the dash curve). It crosses all corrected points A-B-1-3-5 and it can be used to represent experimental results with an error less than $10 \%$. The obtained curve (the calibrated FEM model) takes the second order effects, geometrical imperfection and geometrical orthotropy into account. This model can be used for calculations of hall's arches with diverse spans and in different loading conditions.

The flexural stiffness and membrane stiffness matrices determined at point $\mathrm{E}$ for the simplified and the calibrated model are presented in Fig. 8.

\section{Experimental Methods and Instrumentation}

The analysis of the simplified FEM model had determined the approximate localization of the sensors. The most vulnerable region of the object was expected to be localized in the middle of its height, but due to the complexity of the object, it was difficult to predict the exact position.

It was also expected for the structure to respond with in-plane and out-of-plane displacement components when subjected to load. Moreover, the real shape of the object had to be determined. These are the reasons why the standard pointwise measurement techniques like strain gauges [20] were not suited to this task, even if several sensors were applied. In order to monitor the displacements of the object in a large area of interest, a full-field optical measurement technique has to be utilized. Taking into account all requirements and the range of expected displacements, the 3D Digital Image Correlation method (3D DIC) has been selected as the primary method [21-23].

3D DIC is a non-coherent, image-based method. It measures all components of displacements $(\mathrm{u}, \mathrm{v}, \mathrm{w})$ and the shape of an object. The sensitivity depends on the actual field of view and the resolution of the imagers. The spatial resolution is related to the resolution of the imagers, while temporal resolution depends on the speed of the cameras (number of frames per second). As the 3D DIC method is a full-field optical technique, it is possible to recognize and measure unexpected failures in structures, if only they occurred within the field-of-view (FOV). However, the DIC method is not fully accepted as a standard measurement method for large engineering structures, and therefore this is the reason the displacement measurement at a chosen point were being validated by standard displacement sensors and strain gauges.
Fig. 8 Stiffness matrices of the simplified and calibrated models determined at point $\mathrm{E}$ (Fig. 7) (a)

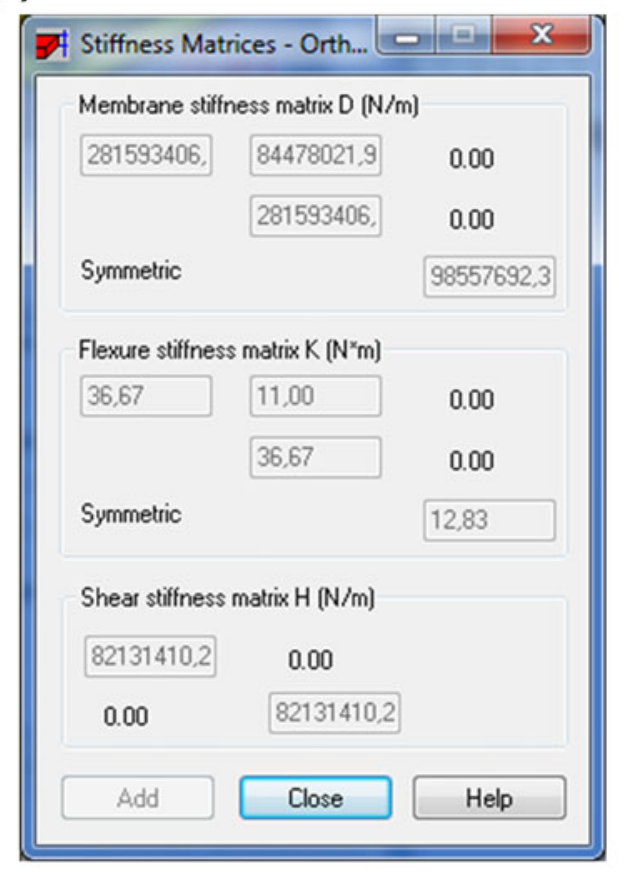

(b)

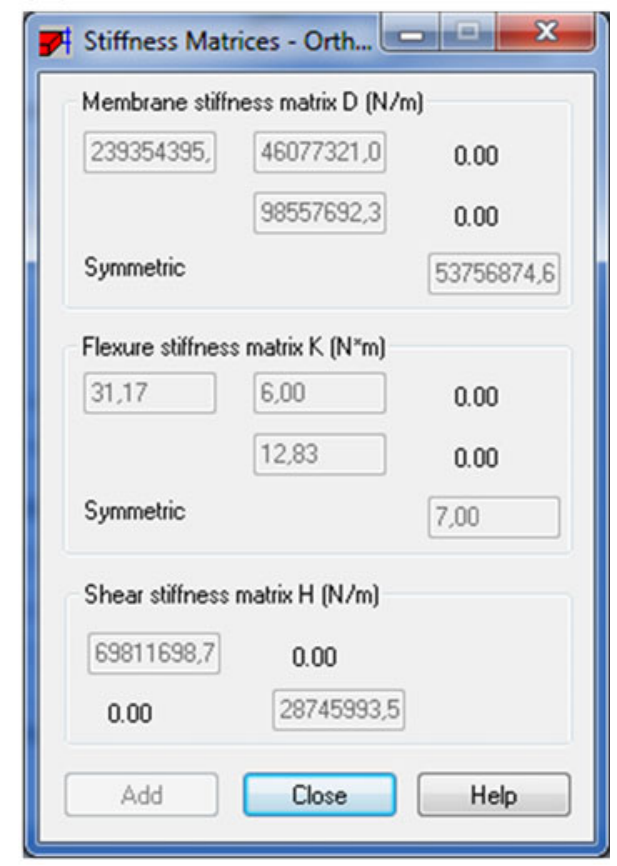




\section{Description of 3D DIC}

DIC is a technique based on the analysis of a pair of digital images (reference and deformed) over a certain area of interest (AOI) taken before and after displacement occurs [22]. The information is extracted from changes of intensity in the images. In the most widely known variation of the DIC, the reference image is divided into small subsets (subimages). The software searches for the most similar subset in all other images, using the maximum cross-correlation function criterion:

$$
C_{\text {normfg }}=\frac{\sum_{i=1, j=1}^{n, m} f(i, j) g(i, j)}{\sqrt{\sum_{i=1, j=1}^{n, m} f(i, j)^{2} \sqrt{\sum_{i=1, j=1}^{n, m} g(i, j)^{2}}}}
$$

where: $f(i, j)$ is the intensity function of the reference image and $g(i, j)$ is the intensity function of the deformed image; $n$, $m$ are pixel dimensions of the investigated subsets.

The center point of the most similar subset found in a deformed image defines the displacement vector. In order to facilitate matching, each subset needs to be sufficiently distinct in the aspect of intensity variations. Therefore a random speckle pattern is applied (e.g. spray paint, sticker paper, water decals) to the object within the AOI. In some cases, when the texture of the measured surface exhibits sufficient intensity variations, there is no need to apply additional random patterns to the object.

3D DIC is a technique, which combines the Digital Image Correlation (for in-plane displacement analysis) with stereovision (for 3D shape measurement) [24]. By using two cameras for observation of the same area of interest, it is possible to obtain the 3D shape of an object. However, both cameras need to be carefully calibrated $[22,25]$ in order to calculate the intrinsic (center of projection coordinates, scale factors and distortion coefficients if required) and extrinsic parameters (describing the geometry of the stereo setup). The stereo matching problem is solved by correlation analysis.

In the experiment, the field of view of the 3D DIC sensor was located at the outer side of the arch. The $2 \mathrm{~m} \times 2 \mathrm{~m}$ area of interest was located $2 \mathrm{~m}$ above the floor (Fig. 9), in the region where the simplified FEM model analysis predicted the largest displacements. The images in the 3D setup were captured by two 2MPx AVT Stingray cameras equipped with Schneider Kreuznach $8 \mathrm{~mm}$ focal length objective lens. The cameras were connected to a laptop via a FireWire
Fig. 9 The experimental setup: (a) the view of the 3D DIC measuring, (b) location of the 3D DIC AOI and loading mechanism, (c) executed loading program (a)

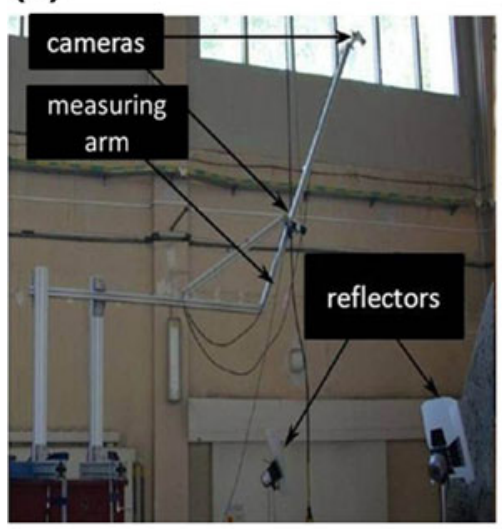

(b)

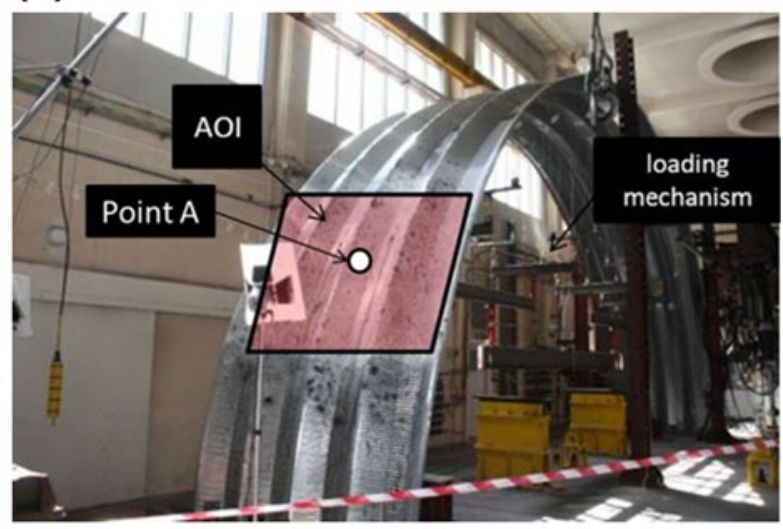

(c)

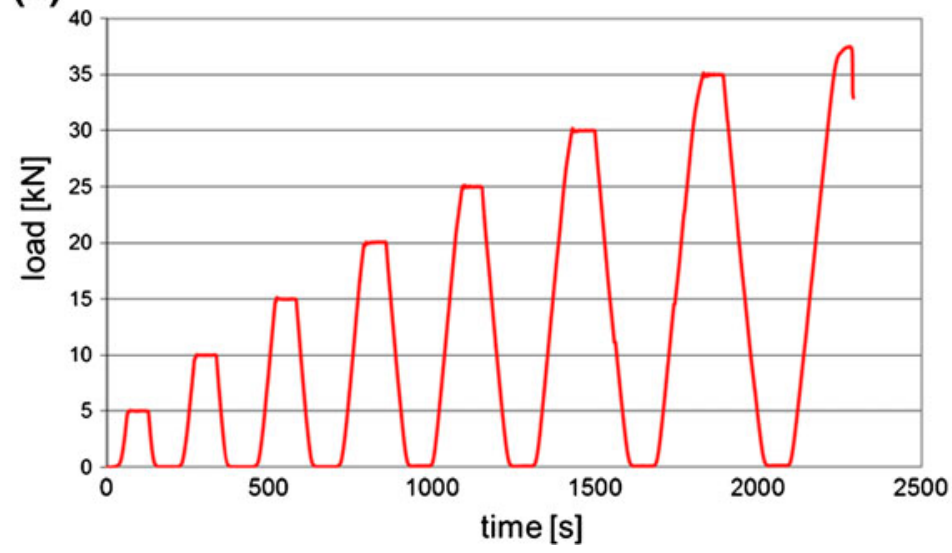


ExpressCard in daisy chain mode. In order to improve lighting conditions, two $650 \mathrm{~W}$ halogen reflectors were used. Because of the large FOV, the cameras were set $1,5 \mathrm{~m}$ apart from each other with a stereo-angle of $30^{\circ}$. The angle is always a trade-off between an image displacements sensitivity and an out-of-plane sensitivity. The value of $30^{\circ}$ introduces modest perspective differences between corresponding image subsets and ensures sufficient out-ofplane sensitivity. According to [22] it is not advisable to maximize the out-of-plane sensitivity at the expense of inplane sensitivity as the same amount of noise in in-plane analysis causes much larger error than if it occurred in outof-plane analysis. The setup was installed on a scaffold made of Bosch Rexroth's aluminium constructional profiles (Fig. 9(a)). The measuring arm has been connected by an articulated joint with a horizontal beam and braced by another, short beam, which was screwed down to the horizontal beam and to the measuring arm itself. The horizontal beam was stiffly mounted to two vertical profiles, which were clamped to a 13-ton constructional steel beam by four G-clampings. The double C-shape steel beam was insulated from the ground by a rubber separating layer. The overall weight of the foundation and the rubber made the scaffold immune to vibrations. It also must be mentioned, that the load of the arch was introduced hydraulically - no motors were used during the test. Thus the influence of the flexibility of the scaffold and the vibration can be neglected.

Images were captured at a frequency of $1 \mathrm{~Hz}$, using a commercial software package called Vic Snap [26]. For the 3D DIC analysis, VIC 3D software (by Correlated Solutions) was used.

The in-plane displacement accuracy obtained by DIC analysis is 0.01 pixels [22], which, considering the field of view $(3 \mathrm{~m})$ and the camera's resolution (1624 pixels) gives a theoretical accuracy of $18 \mu \mathrm{m}$

However, we can expect additional errors due to the divergent local properties of the texture applied at the investigated object and the scaling error during conversion from pixels into micrometers. The experimental accuracy of the in-plane displacement measurement was ultimately estimated at $50 \mu \mathrm{m}$ ( $75 \mu \mathrm{m}$ for out-of-plane displacement).

The measured surface had to be carefully prepared in order to facilitate correlation analysis. The preparation of the surface included cleaning, covering with a ground coat, spraying with white paint and introducing black speckle pattern (with randomly sprayed black paint). Special care was taken to maintain a uniform distribution of the random texture over the AOI. Finally, the measurement area was covered with matte varnish in order to secure the speckle pattern and reduce reflections from the surface. The AOI is an area inside the field of view (FOV) of the sensor which indicates the region where the correlation analysis is to be performed

\section{Pointwise Sensors}

Pointwise sensors were used in order to provide additional data for validation of the correlation measurements results. They were placed inside the most vulnerable regions and within the AOI of the 3D DIC sensor. Two types of sensors were used: an inductive displacement sensor and a set of strain gauges for strain measurements.

The inductive displacement sensor was fixed at the middle of the AOI of the DIC sensor, but on the opposite side of the arch (Fig. 10). The sensor measured absolute displacement (resultant from $\mathrm{U}, \mathrm{V}$ and $\mathrm{W}$ displacements), therefore the data obtained was easy to compare with the corresponding DIC data.

The pointwise sensors were located in the regions where the largest displacements were expected based on the simplified FEM model analysis. The arrangement of the sensors located within the AOI of the 3D DIC sensor has been presented in Fig. 10. The inductive displacement sensor (1) was set at an angle of 30 degrees relative to the ground. The strain gauges (2) were placed at the valleys of the goffering on the outer side of the arch. The strain gauges of the other set (3) were sticked on the peaks and valleys of the goffering on the inner side of the arch. The AOI of the 3D DIC sensor has been marked in red in Fig. 10. All pointwise sensors and a force sensor were coupled in an integrated Hotinger measurement system. The data acquisition frequency was $5 \mathrm{~Hz}$ and it was synchronized with the 3D DIC sensors.

Introduction of Load

Each segment of the measured arch was loaded at four points (which simulate the load introduced by the presence of snow) arranged uniformly along the arch. The measured

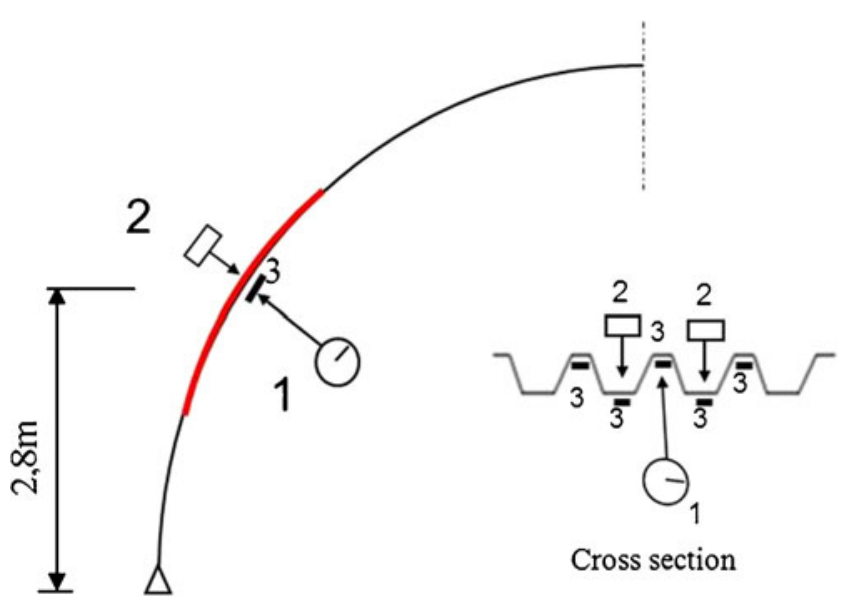

Fig. 10 The arrangement of the pointwise sensors: 1-displacement sensor, 2-strain gauges on the outer side of the arch, 3-strain gauges on the inner side of the arch; the 3D DIC FOV has been marked in red 
object was composed of four arch segments, hence the whole object was loaded in sixteen points.

The load was provided by a set of strings and longitudinal and transverse beams (Fig. 9(b)). The beams were clamping all sets of strings up to the joint with the main beam. A dynamometer and pulley blocks with a hydraulic actuator were fixed to the main beam. The force recorded during the test was therefore the sum of 16 component forces applied to the object. The loading program has been presented on Fig. 9(c).

The loading mechanism ensured a consistent force value, regardless of the deformations of the arch. The total mass of the strings, beams and joints amounted to $518 \mathrm{~kg}$. The control of the loading and data acquisition was automated. The load was introduced gradually in 7 cycles from 0 to $35 \mathrm{kN}$ with an increasing value of load in each cycle equal to $5 \mathrm{kN}$ (Fig. 9(c)). The maximum value of load in a cycle was maintained for approximately $60 \mathrm{~s}$. The last cycle (above $35 \mathrm{kN}$ ) was maintained until the failure of the measured object.

\section{Experiment}

The experiment was carried out within the range of loads specified in Fig. 9(c) and progressed in cycles. The aim of the test was to indicate critical load values and identify shortcomings in the FEM model.
3000 measurements at a frequency of $1 \mathrm{~Hz}$ have been performed by the 3D DIC sensor. All control computers (force, 3D DIC, pointwise sensors) were time-synchronized with each other. The synchronization of all systems facilitated data comparison procedures and ensured more reliable results.

\section{D DIC Results}

The results of the 3D DIC measurement include: the shape map and a set of $\mathrm{U}(\mathrm{x}, \mathrm{y})$ and $\mathrm{V}(\mathrm{x}, \mathrm{y})$ in-plane displacement maps along with the $\mathrm{W}(\mathrm{x}, \mathrm{y})$ out-of-plane displacement map. The shape map of the measured surface is presented in Fig. 11 and the displacements maps are presented in Fig. 12. In the $U(x, y)$ map (Fig 12(a)), the yellow spot indicates the "A" point (Fig 9(b)), where the displacement sensor was located. The comparison of the displacement data obtained by DIC and inductive sensors was needed in order to validate the results obtained from $3 \mathrm{D}$ DIC and to eliminate the possibility of a gross error.

The 3D DIC method provided a large amount of information. Figure 12 presents example displacement maps calculated for a high load value. In the middle section of the FOV, large displacement gradients can be observed. In order to track the failure process and visualize the asymmetry of displacements maps, we extracted three components of displacement vectors at points along two chosen lines (in arcwise direction) (marked as white lines L1 and L2 at the U displacements map in Fig. 12).
Fig. 11 Initial 3D shape map for the AOI at the arch surface

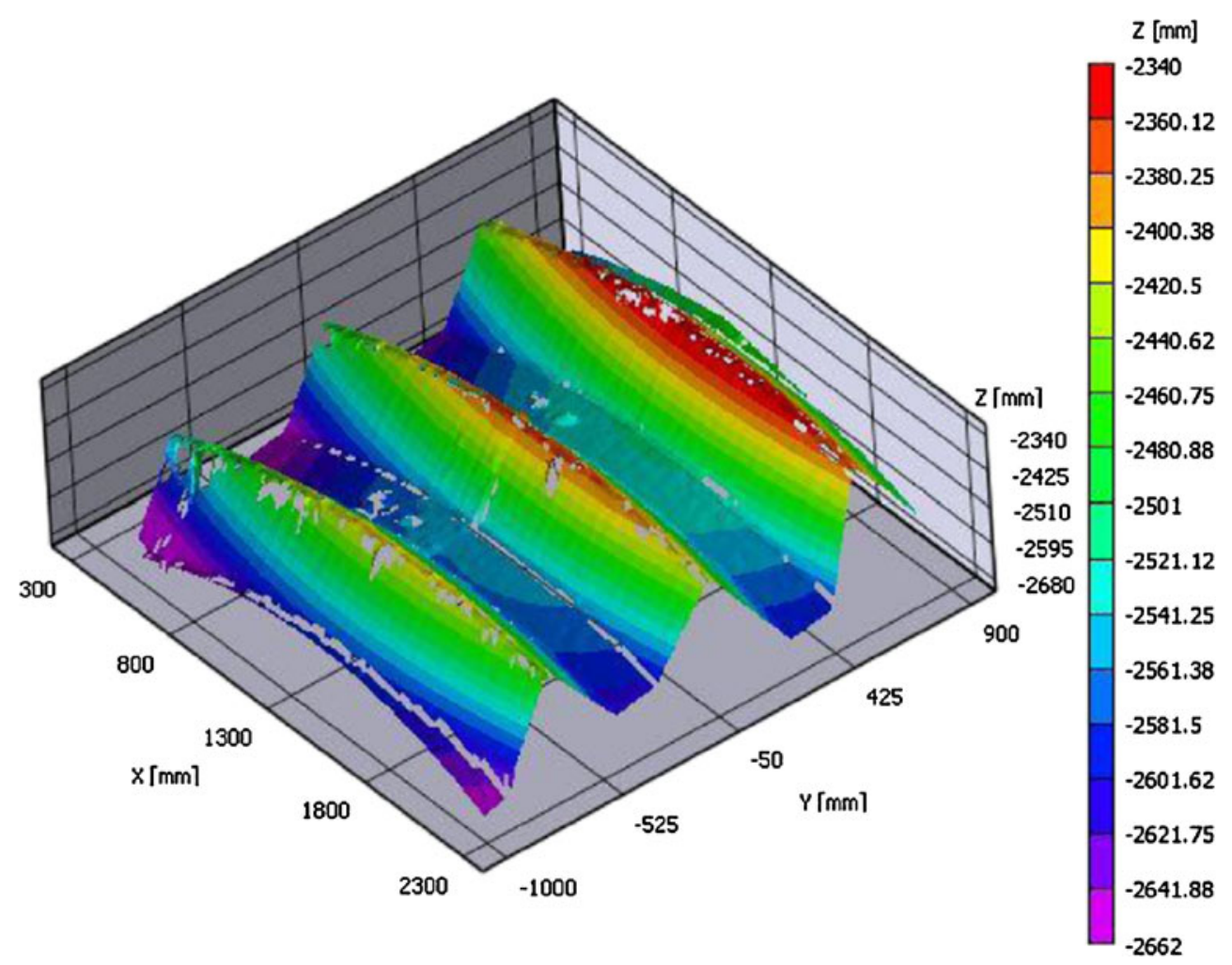


The extracted $\mathrm{U}, \mathrm{V}$ and $\mathrm{W}$ displacements have been presented in Fig. 13 in the function of time. Such presentation of the data shows the development of a characteristic deformation in the area of failure (line L1). The failure process begins at $25 \mathrm{kN}$ load (which can be observed in $\mathrm{V}$ displacements along L1). At the maximum load, the largest $\mathrm{U}$ and $\mathrm{V}$ displacement values occur within the A crossection (Fig. 13). W displacements were more pronounced within the B crossection, which is consistent with the numerical predictions. An interesting conclusion can be drawn from the comparison between deformations along line L1 and line L2. The red area in Fig. 12 indicates riveted joints between neighboring metal plates sections. The L2 line was extracted from a region reinforced by these joints. In the region from which line L1 was extracted, the connections between neighboring sections were located to the top and to the bottom of the FOV. As one can observe in Fig. 13, the failure process did not occur in the region with joints (line L2) because the structure was more stable there.

\section{Verification of the 3D DIC Results}

In order to enable a more reliable comparison with results obtained from the displacement sensor, absolute displacement values were calculated. The sensor was located at the opposite side of the metal plate in relation to the $3 \mathrm{D}$ DIC AOI. The location of the sensor was marked to facilitate the identification of the precise spot. Plots of absolute displacements at Point A as obtained from both sensors are presented in Fig. 14. The analysis proved the measured displacement values of the two sensors to be very close. The maximum discrepancy of measurements is less than $2 \%$. The small discrepancies could be caused by the fact that the sensors were monitoring the opposite sides of the metal plate. In Fig. 14, displacements extracted from the same point in the numerical model have been also presented.

An another comparison was made in order to validate strain measurements. Displacement maps, which are the primary output quantities from the correlation calculations, can be consequently differentiated to obtain strain maps. Here in order to obtain a more reliable comparison, the following procedure was implemented. A virtual extensometer was placed next to the strain gauge in a fragment of the AOI of the DIC sensor. Displacement values were extracted from displacement maps at two points, which can be treated as contact points between the virtual extensometer and the measured surface. The distance between these points and their locations matched the strain gauge parameters in respect to the base length, and the direction of measurement (the virtual extensometer was placed parallel to the strain gauge). The extracted displacement values were consequently used to obtain the strain value at a chosen moment in time (' $\mathrm{t}$ '):

$\varepsilon(t)=\frac{\operatorname{disp}_{A}(t)-\operatorname{disp}_{B}(t)}{L}$

where $\operatorname{disp}_{A}(\mathrm{t})$ and $\operatorname{disp}_{B}(\mathrm{t})$ are displacements extracted at time ' $\mathrm{t}$ ' at points $\mathrm{A}$ and $\mathrm{B}$ respectively and $\mathrm{L}$ is the distance between point $A$ and point $B$. Strain calculations were carried out on pixel values, so the presented results are free from a scaling error.

The "virtual extensometer" and strain gauge were very close to each other, but still somewhat separated, since the correlation analysis could not be performed inside the area where the strain gauge covered the speckle pattern.

In Fig. 15, a comparison plot between strains calculated through the procedure described above and the strains measured by a strain gauge is presented.

The comparison indicated sufficient correlation between the results obtained from the virtual extensometer and the strain gauge in the elastic range. Discrepancies grow fast

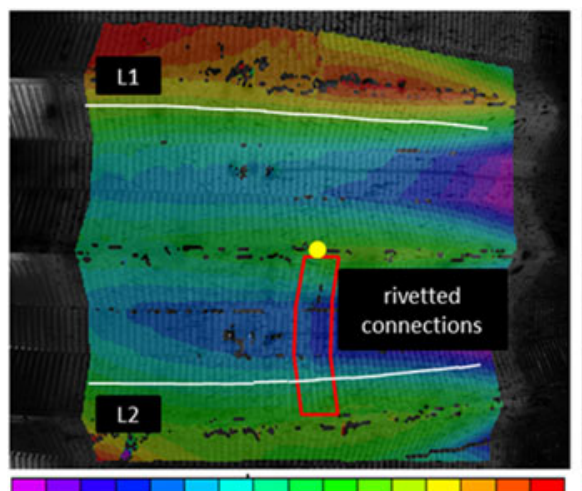

26,4
U $[\mathrm{mm}]$

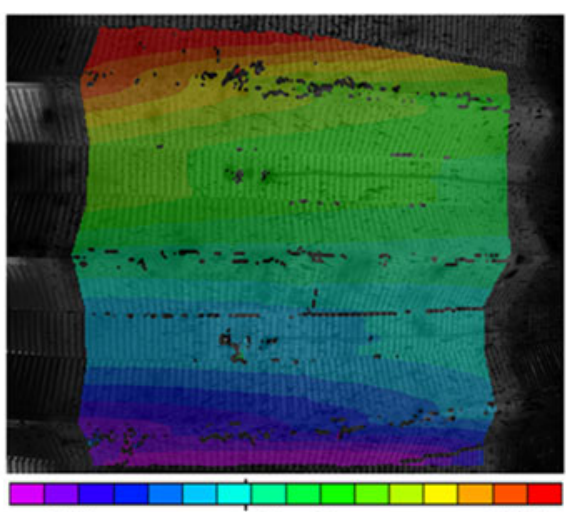

$-40,5$

$\mathrm{V}[\mathrm{mm}]$

33,5

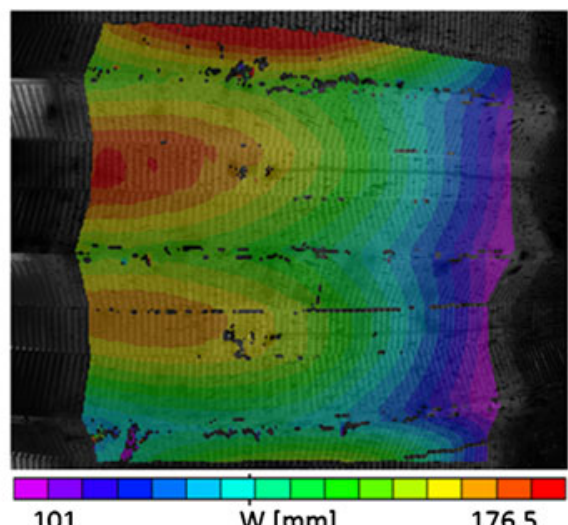

Fig. 12 Example displacement maps: $U(x, y), V(x, y)$ and $W(x, y)$; lines $L 1$ and L2 overlaid on the $U(x, y)$ map were used to generate the visualization of the displacements in time as shown in Fig. 13; the red curve indicates riveted joints between neighboring metal plates segments 
(a)
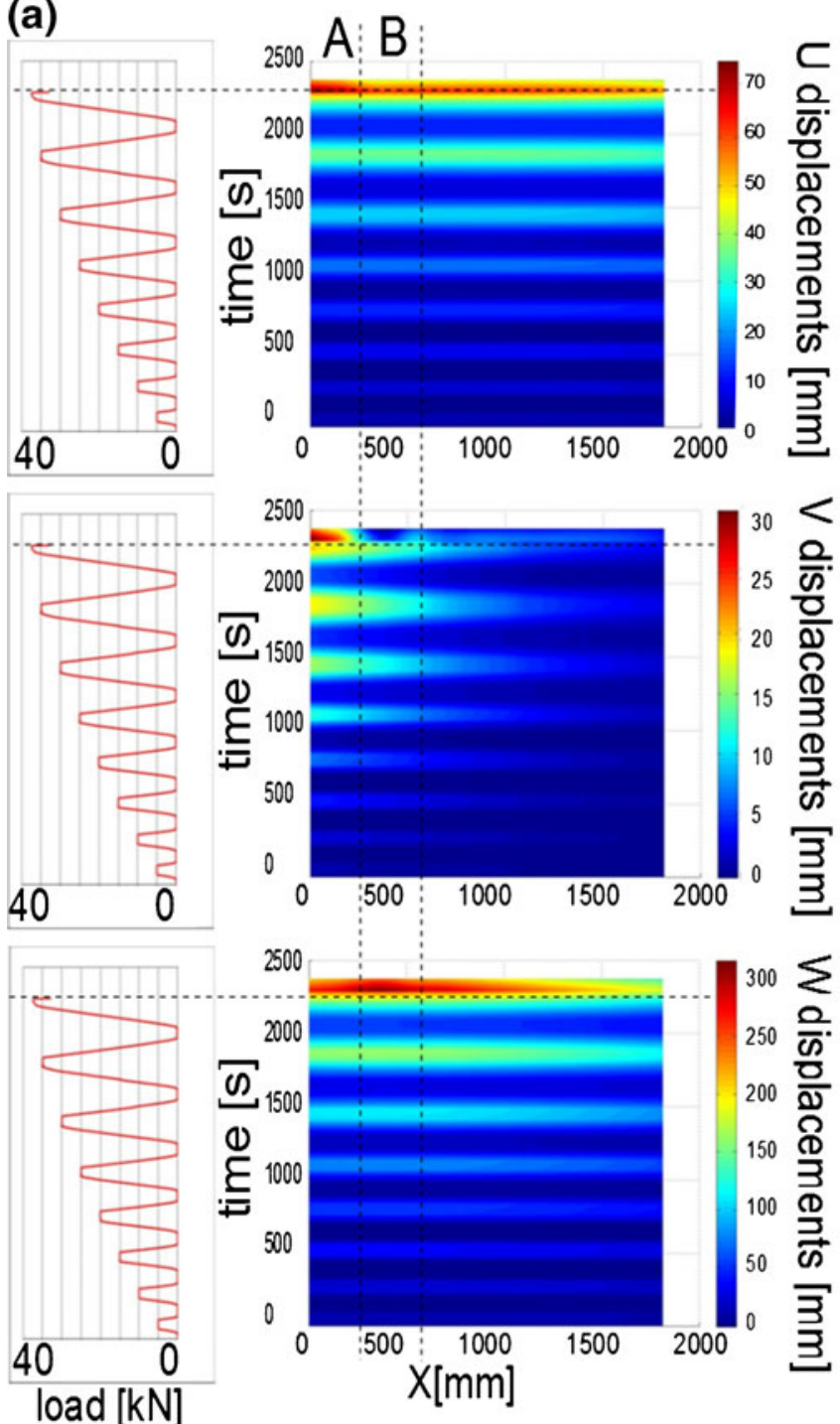

(b)
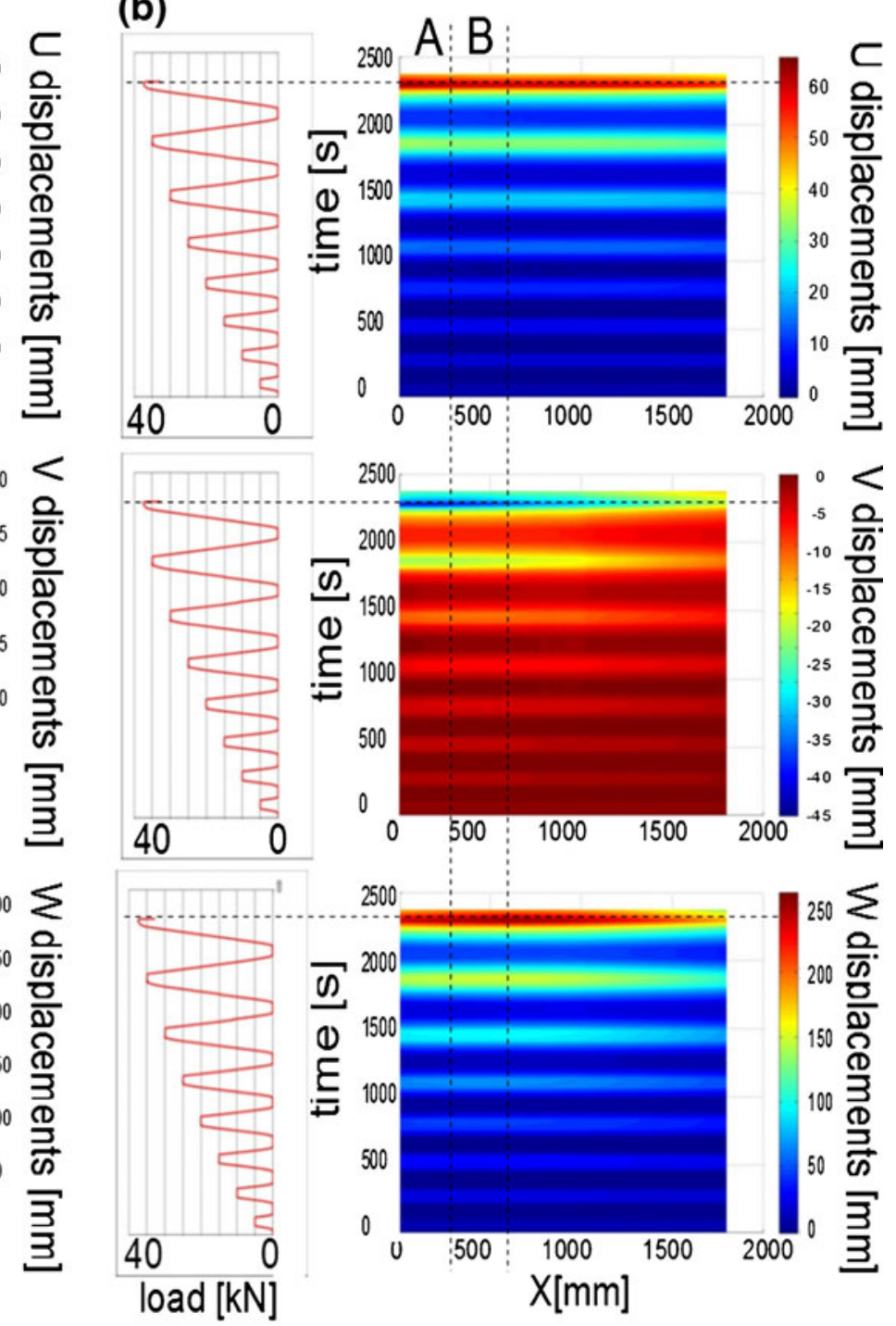

Fig. 13 Representation of U, V, W displacements along two chosen lines (a) L1 and (b) L2 from Fig. 12 in the function of time; at the left hand side of the color maps, the load program is provided

Fig. 14 Absolute displacement measured by DIC,

the displacement sensor and generated from the numerical model

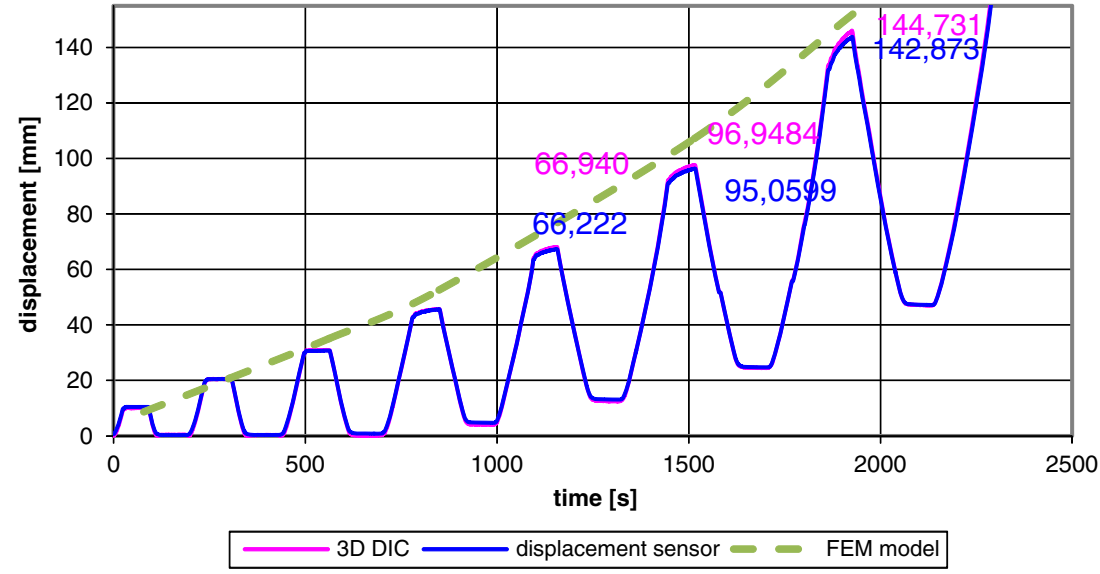




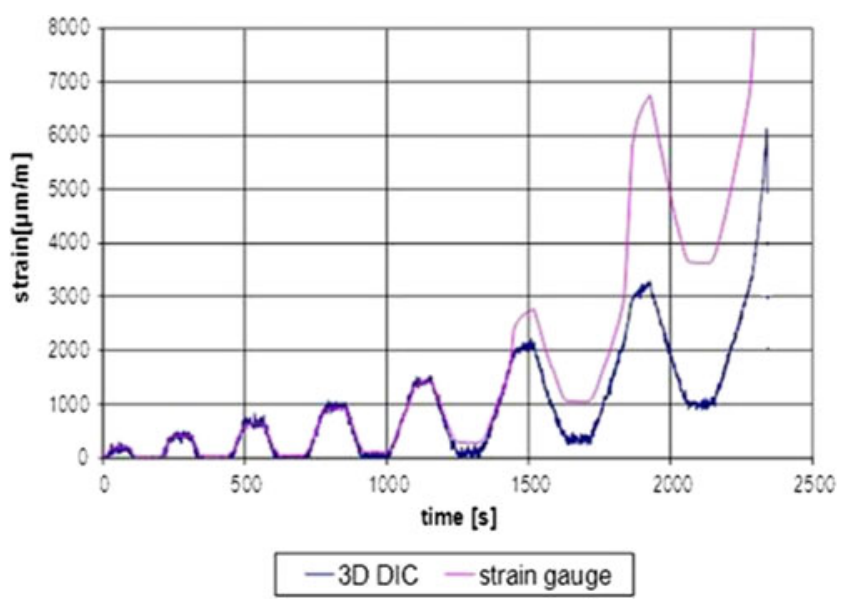

Fig. 15 Comparison of the strain measurement performed by the virtual extensometer and strain gauge

when the structure reaches the plastic range. It was a limit of the utilized strain gauge, which exceeded its range and came unstuck from the surface. The application of the strain gauge was additionally hindered because of the goffering of the metal plates. The discrepancies caused by local loss of stability are small and can be neglected.

\section{Comparison Between Numerical and Experimental Data}

The most important issue in regard to the comparison of the test data with numerical data was matching the coordinate systems. All DIC results were initially related to a coordinate system which is assigned by the geometrical DIC configuration. The 'xy' plane was perpendicular to the axis of the sensor (which was located in the middle of the distance between the optical axes of both cameras). In order to reliably compare the results obtained from the experiment with the results numerically generated from the FEM model, it was necessary to transform the data from the DIC coordinate system into the FEM model's coordinate system (or inversely).

In the FEM method, each finite element has its own, local coordinate system, in which in-plane displacements or strain, and out-of-plane displacements are calculated (Fig. 16). In 3D DIC the coordinate system is associated with the AOI and hence quantitative comparison of displacement components obtained from numerical simulations and from the experimental results can only be performed inside a small region at the centre of the AOI (where the directions of the coordinate systems are the same). In order to compare displacement components outside the centre of the AOI, local coordinate systems' transformations need to be performed.

In order to calibrate the detailed FEM model (according to the procedure presented in the "Detailed FEM model section"), absolute displacements' values from the experiment (which are a square sum of all displacement components) have been used, as they could be quantitatively compared with numerical results. The obtained experimental data was introduced into the detailed FEM model. Displacements determined through the experiment were compared with numerical simulations. In order to calibrate the model (to match experimental data and numerical simulations), the flexural stiffness matrix was altered. The calibration procedure has been presented schematically in Fig. 7. Discrepancies between the numerical model and the real object are lower than $10 \%$. This validates the utilization of the detailed and calibrated FEM model for the investigation of objects made of similar metal plates but at a different scale. More data points from the experiment could be used to further diminish the gap between the model and the real object.

The consequent analysis of the calibrated, detailed FEM model aimed to determine the critical load in respect to the global buckling and the local loss of stability. The result of these calculations is the critical load for the first (and the most probable) mode of buckling. The view of the FEM model subjected to critical load has been compared with the real image of the object under experimental load (Fig. 17).

At Point 1, buckling can be observed, while at Point 2 the metal plate broke as a result of loss of stability. During the experiment, the loss of stability occurred for the $37.4 \mathrm{kN}$ summarized load, which matches the numerically calculated value $(36,6 \mathrm{kN})$ very well. Such good correspondence between the FEM model and the real object test results allows to conclude that the model calibration was performed correctly.

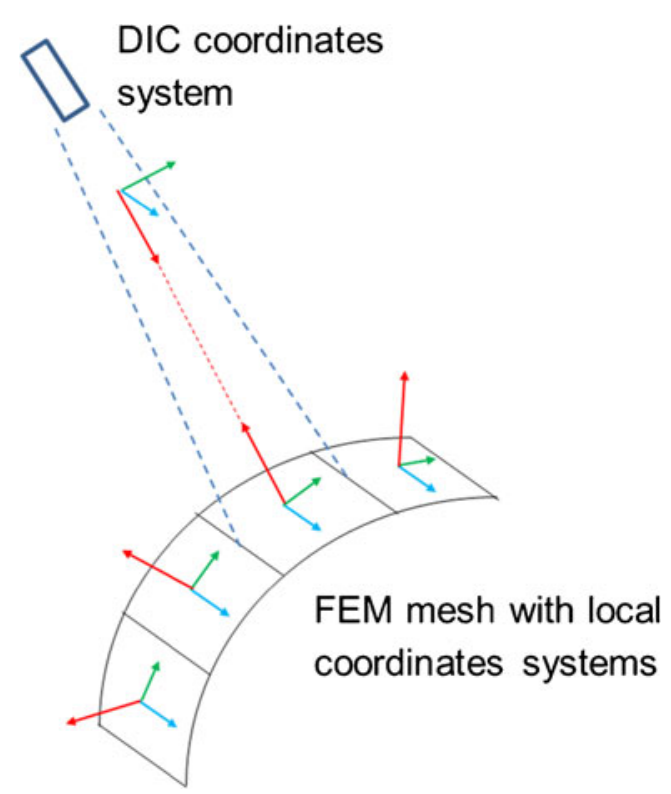

Fig. 16 3D DIC sensor coordinate system orientation and FEM local coordinate systems 

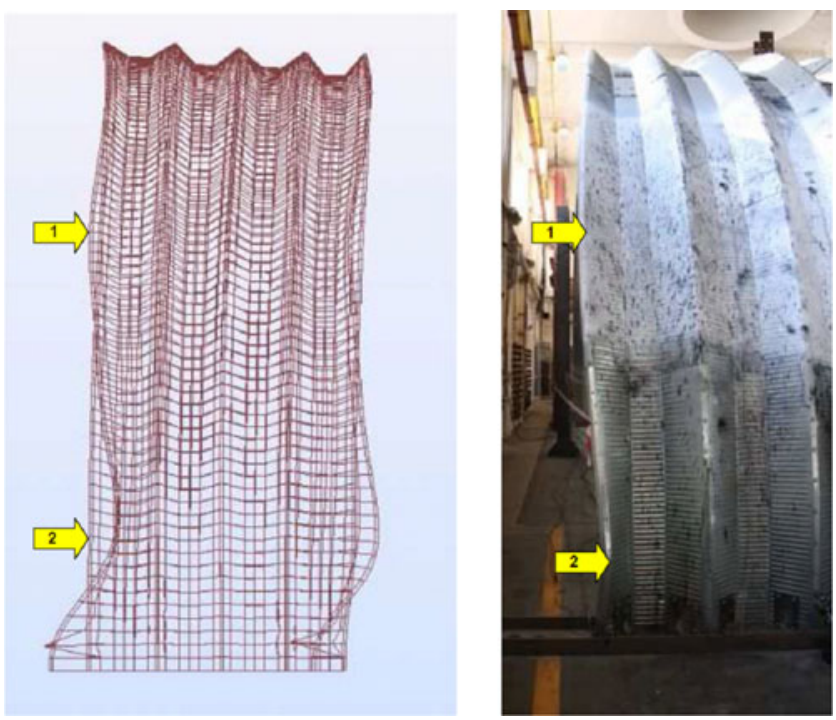

Fig. 17 Views of the model and the object during the experiment; the mesh grid of the model has been rescaled for better visualization, original mesh was finer (it contained 4176 finite elements)

The critical load, calculated by means of numerical analysis, was used for creating displacement maps within the AOI of the 3D DIC sensor. The example results (for $5 \mathrm{kN}$, $15 \mathrm{kN}$ and $30 \mathrm{kN}$ ) have been presented in Fig. 18 (the maps obtained from the DIC sensor have been rotated by 90 degrees in order to facilitate visual comparison). The coordinate systems are compatible in the centre of the FOV only and in this region displacement's components can be quantitatively compared. Because of the specific qualities of the measured object, $\mathrm{U}$ and $\mathrm{V}$ displacements were not compared with experimental results.

Visual comparison of the maps presented in Fig. 18 indicates good correspondence between numerical and experimental data. However, a certain asymmetry in experimental results due to an additional linear component of displacement (tilt of the structure) can be observed.

\section{Discussion}

The comparison of the results obtained from the experiment and FEM simulations at the indicated object points showed that they correspond very well. Additionally, the experiment allowed to observe the failure process at the bottom right corner of the structure (Fig. 17).

The discrepancies in displacement measurements could be caused by the fact that the DIC and the displacement sensors were located on the opposite sides of the metal plate. Discrepancies and errors in strain measurements were probably caused by the shape irregularity of the surface measured by the strain gauges. The locations of the comparison points were shifted by a small value from the actual locations of pointwise sensors, as 3D DIC analysis could not be carried out at the precise regions where the strain gauges were attached.

The comparison between experimental data and the detailed FEM model showed very good consistency after just the first iteration of the experimental-numerical hybrid measurement methodology (thanks to the efficient prediction of the failure regions in the simplified model). Therefore, it was not necessary to perform additional tests. In more complicated cases, when the simplified FEM model would not give clear information about the region of failure, it is still economically more efficient to perform more laboratory tests on 1:1 scaled models than to install a SHM system.

To conclude the whole measurement effort, critical loads and vulnerability regions of the object were determined. The detailed FEM model (which includes corrections from the experimental data) can also be used for more precise simulations of accidental load conditions.

The analysis of 1:1 scale models of low-cost civil engineering structures can be a very efficient way to improve the safety of such structures. The 3D DIC method is an easy full-field experimental technique, which provides high accuracy data important to the development of a proper FEM model of the structure.

The 3D DIC method provided large amounts of data, which can be analysed and visualized in many different ways in order to facilitate the evaluation of experimental results. The $4 \mathrm{D}$ visualization (Fig. 13) presented in the article can be applied and utilized to track deformations along chosen lines as functions of time, which is a great convenience, e. g. in crack propagation investigation.

\section{Conclusions}

The hybrid method for laboratory measurements of lowcost, large scale building structures has been presented in this paper. A 1:1 scale model of the hall's arch made of goffered metal plate has been created and subjected to load, which simulated the natural influence of the presence of snow on the roof. FEM model simulations were complemented by the experimental data and good correspondence has been achieved. Additionally, the failure process has been observed, localized and consequently used for the improvement of the initially created simplified FEM model. The detailed model has been calibrated by manipulating the flexural and membrane stiffness matrices in order to close the gap between the FEM simulations and the experimental data. A discussion in respect to error sources, future works and usability of the method, has been included.

As a result of hybrid testing (with application of traditional and modern, full-field optical methods) and in reference to the simplified FEM model, the calibrated, detailed 
(a)
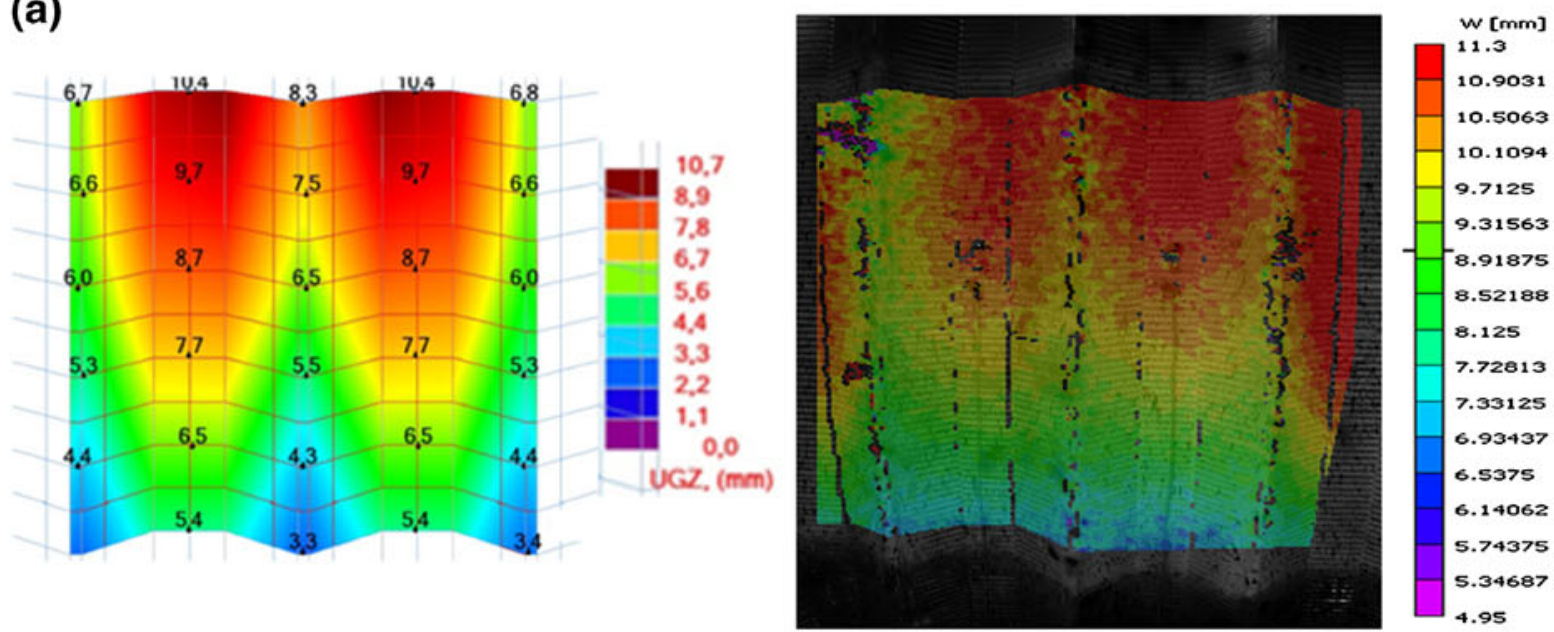

(b)
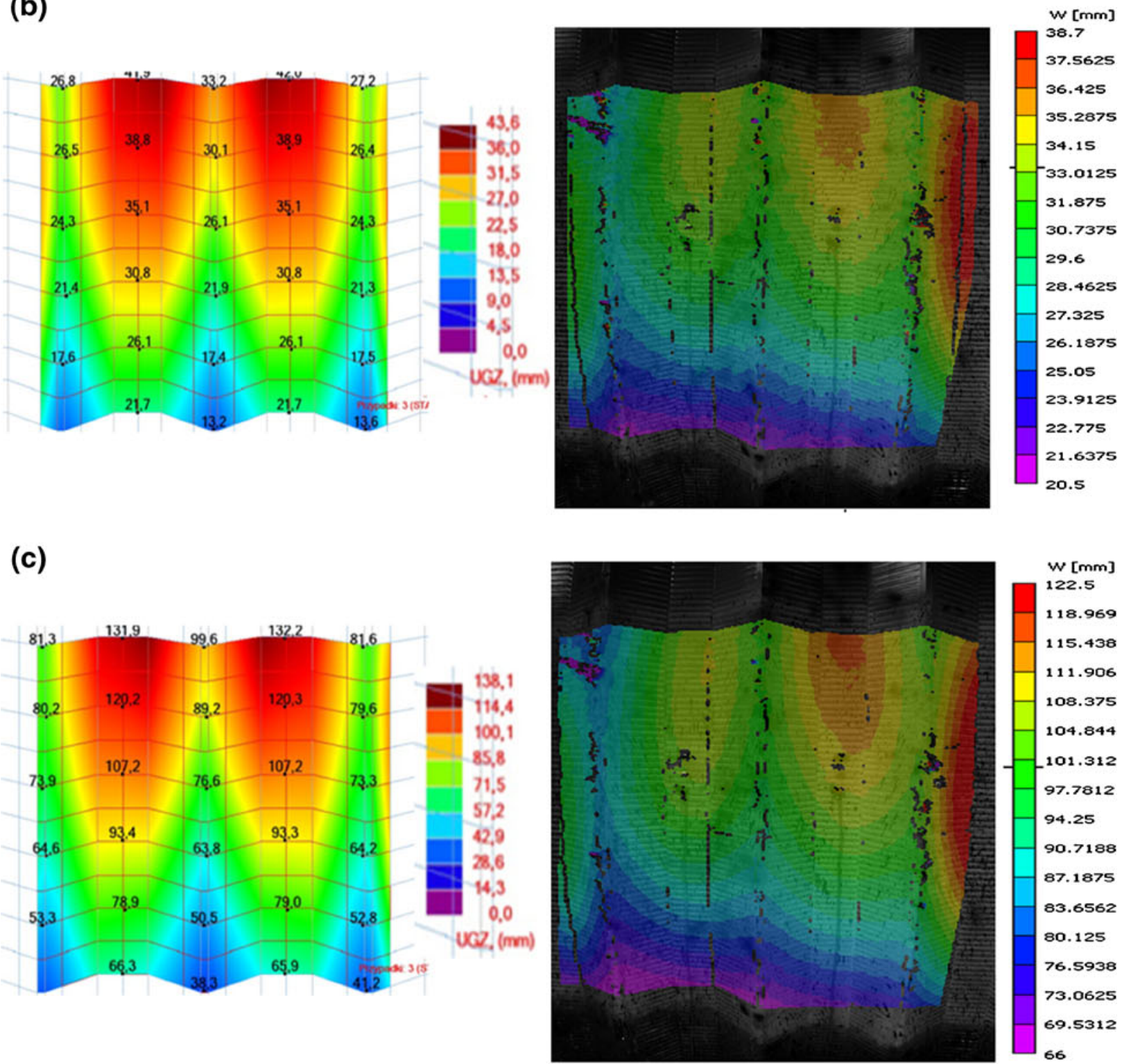

Fig. 18 W displacements maps obtained by FEM modeling and 3D DIC sensor respectively for the loads: (a) $5 \mathrm{kN}$, (b) $15 \mathrm{kN}$ and (c) $30 \mathrm{kN}$ 
numerical model of the large object has been designed. The model has been used consequently to transfer mechanical properties onto the real object with regard to support and foundation conditions. The hybrid methodology provided the FEM model, which can be used to carry out simulations of similar objects at a large scale.

The hybrid measurement technique, applied to low-cost, large scale engineering structures with a typical construction and shape gives new opportunities to engineers and assist in effective and rational design. The overall costs of such a preoperating test are much smaller than the alternative SHM systems.

Future work will concern measurements of 1:1 scale models of halls manufactured in single shell and double shell (two metal plates arches with an insulating layer between them) variants with different cross-sections of profiles and different types of joints between sections. The aim of the tests will be to establish consistent design methods of arch coverings for low-cost civil engineering structures, which include the influence of utilization conditions, loading conditions and different methods of shaping of the arches.

Acknowledgement The financial support from the statutory funds of the Warsaw University of Technology and the project "Health Monitoring and Lifetime Assessment of Structures" - MONIT POIG.0101.02-00-013/08-00 financed through the EU Structural Funds in Poland are gratefully acknowledged. The authors thank to Paweł Więch and Zbigniew Fedorczyk from the Building Research Institute and to Bartłomiej Siwek from the Institute of Micromechanics and Photonics for the valuable support in performing the experiments with the 1:1 scale model of the hall's arch.

Open Access This article is distributed under the terms of the Creative Commons Attribution License which permits any use, distribution, and reproduction in any medium, provided the original author(s) and the source are credited.

\section{References}

1. Biegus A, Rygaluk K (2009) Collapse of Katowice fair building. Engineering Failure Analysis 16(5):1643-1654

2. Buidling Research Institute's archive (in Polish)

3. www.tgbuildings.com (in Polish)

4. Biegus A (2003) Analiza statyczno - wytrzymałościowa łukowych blach fałdowych. Konstrukcje Stalowe, (in Polish)

5. Housner GW, Bergman LA, Caughey TK, Chassiakos AG, Claus RO, Masri SF (1997) Structural control: past, present, and future. Journal of Engineering Mechanics 123(9):897-971

6. Chana THT, Yua L, Tamb HY, Nia YQ, Liub SY, Chung WH, Cheng LK (2006) Fiber Bragg grating sensors for structural health monitoring of Tsing Ma bridge: background and experimental observation. Engineering Structures 28(5):648-659

7. Rodriguesa C, Félix C, Lagec A, Figueiras J (2010) Development of a long-term monitoring system based on FBG sensors applied to concrete Bridges. Engineering Structures 32(8):1993-2002

8. Berninia R, Minardo A, Zeni L (2007) Accurate high-resolution fiber-optic distributed strain measurements for structural health monitoring. Sensors and Actuators A: Physical 134(2):389-395

9. Ko JM, Ni JQ (2005) Technology development in structural health monitoring of large-scale bridges. Engineering Structures 27 (12): $1715-1725$

10. Huang YH, Liu L, Sham FC, Chan YS, Ng SP (2010) Optical strain gauge vs. traditional strain gauges for concrete elasticity modulus determination. Optik - International Journal for Light and Electron Optics 121(18):1635-1641

11. Shoukry SN, Riad MY, William GW (2009) Longterm sensorbased monitoring of an LRFD designed steel girder bridge. Engineering Structures 31(12):2954-2965

12. Tennyson RC, Mufti AA, Rizkalla S, Tadros G, Benmokrane B (2001) Structural health monitoring of innovative bridges in Canada with fiber optic sensors. Smart Material Structures 10:560-573

13. Li H-N, Lia D-S, Song G-B (2004) Recent applications of fiber optic sensors to health monitoring in civil engineering. Engineering Structures 26(11):1647-1657

14. Krezel J, Kujawinska M, Dymny G, Salbut L (2008) Design and testing of low-cost full-field integrated optical extensometer. Proc, SPIE 7003:70030X-70030X-7

15. Kujawinska M, Sitnik R, Dymny G, Karaszewski M, Michonski K, Krzeslowski J, Mularczyk K, Bolewicki P (2009) Remote online monitoring and measuring system for civil engineering structures. Proc SPIE 7389:738904-1-10

16. Kujawińska M, Sitnik R, Dymny G, Malesa M, Malowany K, Szczepanek D (2010) Hierarchical, multitasks optical system for health monitoring of civil engineering structures. Proc SPIE 7387:738721

17. Patorski K (1993) Handbook of the Moire Fringe technique. Elsevier

18. Malesa M, Kujawinska M, Szczepanek D, Swiercz A, Kolakowski $P$ (2010) Monitoring of civil engineering structures using DIC technique. EPJ 6:31014

19. Laermann K-H (2000) Hybrid techniques in experimental mechanics. In: Learmann K-H (ed) Optical methods in experimental solid mechanics. Springer, NewYork

20. Pan B (2010) Recent Progress in Digital Image Correlation, Experimental Mechanics, Online Firsr, doi:10.1007/s11340-0109418-3

21. Kobayashi AS (1993) Handbook on experimental mechanics. SEM

22. Sutton M, Orteu J-J, Schreier H (2009) Image correlation for shape, motion and deformation measurements. Springer

23. Pan B, Qian K, Xie H, Asundi A (2009) Two-dimensional digital image correlation for in-plane displacement and strain measurement: a review. Measurement Science and technology 20 (6):062001

24. Orteu J-J (2009) 3-D computer vision in experimental mechanics. Opt Lasers Eng 47:282-291

25. Bradski G, Kaebler A (2008) Learning OpenCV: Computer Vision with the Open CV Library. O'Reilly

26. www.correlatedsolutions.com 